\title{
L2 Learner Cognitive Psychological Factors About Artificial Intelligence Writing Corrective Feedback
}

\author{
LiQin $\mathrm{Wu}^{1}$, Yong $\mathrm{Wu}^{1} \&$ Xiang Yang Zhang ${ }^{1}$ \\ ${ }^{1}$ School of Languages and Media, Anhui University of Finance and Economics, Bengbu, China \\ Correspondence: LiQin Wu, School of Languages and Media, Anhui University of Finance and Economics, 255 \\ Hongye Road, Bengbu, Anhui, China.
}

Received: September 4, 2021

Accepted: September 24, $2021 \quad$ Online Published: September 26, 2021

doi: $10.5539 /$ elt.v14n10p70

URL: https://doi.org/10.5539/elt.v14n10p70

\begin{abstract}
Although the study of artificial intelligence (AI) used in language teaching and learning is increasingly prevailing, research on language two (L2) learner cognitive psychological factors about AI writing corrective feedback (WCF) is scarce. This paper explores L2 learner cognitive psychology of pigai, an AI evaluating system for English writings in China, from perspectives of perception, noticing, uptake, initiative, retention and emotion. It investigates the consistency between learner cognitive psychology about AI WCF and the expected one and probes into the correlation of learner cognitive psychological factors about AI WCF, aiming at bridging the gap between the research of AI WCF and that of L2 learner cognitive psychology. After a 5-point Likert anonymous questionnaire survey of 1952 undergraduate L2 learners in Anhui University of Finance and Economics (AUFE), the statistical data of Pearson correlation coefficient indicate that learner perception, noticing, uptake, initiative, retention and emotion are positively related in the context of AI WCF, which conforms to the early research of learner cognitive psychology about WCF. But one sample t-test reveals that learner cognitive psychology of AI WCF only occasionally or sometimes consists with the expected one. The subsequent random interviews with 15 respondents suggest that pigai WCF is beneficial to L2 writing, yet there is still much room for it to improve to be deeply integrated with human WCF.
\end{abstract}

Keywords: L2 learner, cognitive psychology, AI, WCF

\section{Introduction}

Research on L2 learner cognitive psychology shows that L2 learner cognitive psychology is reflected from factors like perception, attention, behavior, emotion, motivation, cognition, memory, et al. These factors are reported to be interrelated with one another and may bring about different expected teaching or learning effects. Fredricks et al. (2004) argue that learner behavior, emotion, and cognition are three major elements that are bound and interconnected and might influence learning effects. Cognition and emotions influence human behaviors (Pessoa, 2008), and learning behavior influences learning effects. Positive learning behavior, i.e., the positive involvement in all kinds of academic tasks, is essential to positive academic effects. It is true of the emotion. Positive (interest, happiness) or negative (boredom, sadness, and anxiety) emotion might trigger likewise responses to learning. Cognition, which concerns learner psychological investment and learning strategy, entails understanding complex ideas and mastering sophisticated skills (Zhang \& Hyland, 2018).

AI technology that is now extensively used in L2 teaching and learning has undergone a breakthrough from the initial computer-aided education (Akbulut, 2007; Mohsen \& Balakumar, 2011) to the current advanced technology by combining computers with machines to simulate the human mind to solve problems and make decisions. It has been applied to L2 writing rating (Ai, 2017; Cotos, 2010; Koltovskaia, 2020) and L2 writing translation (Chon, 2021).

However, research on AI technology application in L2 teaching and learning is limited. Research on L2 learner cognitive psychology of AI WCF is even sparse, which involves complex and multidisciplinary knowledge of AI technology, linguistics, cognitive psychology and so on. The present scanty research on L2 learner cognitive psychology and AI WCF (Koltovskaia, 2020; Zhang \& Hyland, 2018) suggests that learner engagement plays an essential role in AI WCF. It is revealed that teacher CF and automated CF have their merits and demerits, but learner engagement has great effect on L2 writing development. Modelling human learning and memory is found 
possible by means of AI technology (Riedesel et al., 2017). And it turns out to be successful in tuning the algorithm to give a high probability that the simulated learner answers each item correctly.

Gaining a deep insight into L2 learner cognitive psychology about AI WCF is of great significance to the quality improvement of AI WCF so that AI technology can be more widely applied in language teaching and learning. As is mentioned above, despite the study of L2 learner cognitive psychology is increasingly prevailing, research on L2 learner cognitive psychology in the context of AI WCF is scarce. Therefore, this research attempts to find out L2 learner cognitive psychology of pigai from the perspectives of perception, noticing, uptake, initiative, retention and emotion and bridge the gap between the research of AI WCF and that of L2 learner cognitive psychology.

\section{L2 Learner Cognitive Psychology and AI WCF}

L2 learner cognitive psychology is mainly concerned with the scientific study of L2 learner perception, attention, memory, emotion, learning, remembering, thinking, understanding, reasoning and so on. This paper concentrates on perception, noticing, uptake, initiative, retention and emotion.

AI is applied in academic discourse evaluating and proven to be an effective formative assessment tool suitable for implementation in the targeted instructional context (Cotos, 2010). It is used in WCF, too. For instance, the study of the learner engagement indicates learners differ in levels of engagement with intelligent or automated WCF (Koltovskaia, 2020), and these levels of cognitive engagement may be crucial to the outcome of L2 learning. On the other hand, over-reliance on intelligent or automated WCF may result in limited cognitive engagement and blind acceptance. So far, however, most research on AI has been linked either with cognitive psychology or with WCF, it is hard to find the study of L2 learner cognitive psychology in the context of AI WCF.

\subsection{Perception, Noticing, Emotion and AI}

For L2 learners, perceiving the corrective nature of feedback is a must for L2 learning. If learners' perceptions differ from their teachers' intention, they may not benefit from feedback (Amrhein \& Nassaji, 2010). Neither will learners benefit from pigai if they do not perceive it as they are supposed to. Positive perception is often associated with positive outcome, or vice versa.

Schmidt's (1990) Noticing Hypothesis posits that "input does not become intake for language learning unless it is noticed, that is, consciously registered". Noticing is a prerequisite for transforming input into intake, and subliminal language learning is impossible for intake. And noticing is sometimes interchangeable with attention, but like many psychological constructs, attention does not refer to a single mechanism but to a variety of mechanisms, including alertness, orientation, detection within selective attention, facilitation, and inhibition (Schmidt, 1990; 2012; Tomlin \& Villa, 1994). Attention can help separate the useful input from the “overwhelming" one (Tomlin \& Villa, 1994).

Emotion, an influential factor in learning, is also studied by using AI technology. The emotion recognition model proposed by Cui \& Wang (2021) can detect and monitor the learner emotional states. Upon detecting frustration or boredom, the AI system will make timely adjustment to what interest the learners or what are easier for them to learn to keep them in an active state of learning. Apart from that, Niedenthal's (2007) research on the relationship between eye gaze and facial expression provides cues for automatic expression analysis systems to explore facial expression recognition.

Emotion and attention are inseparable from each other. Learner emotion is likely to affect their attentional processes (Liu et al., 2009), and the efficient selectivity of attention would predict the subsequent affective assessment of visual stimuli (Kiss et al., 2007). Attention can also produce positive or negative learning effects (Fenske et al., 2005; Zhou et al., 2007). For example, attended stimuli are rated more positive than the unattended one (Liu et al., 2009).

Emotion together with motivation is essential to learner perception, attention, executive control, and decision making (Kiss et al., 2007; Langeslag et al., 2008). Romantic love increases learner attention for stimuli, and this type of attention differs from the task-based one (Langeslag et al., 2008). In their experiment, Zhou et al. (2007) adopt a variant of artificial grammar learning (AGL) paradigm, and find that the emotion of "dislike" toward previously inhibited stimuli is contagious because it can be spread to the previously unseen stimuli of the same family. This finding about the interaction between three major systems of the human brains (affective, attentional and information acquisition systems) is of great significance to L2 learning. 


\subsection{Uptake, Retention, Initiative and AI}

Learner uptake and retention may be influenced by the linguistic errors (the type of writing errors) that the learners make or by affection (attitudes, beliefs, and goals) that learners have for the writing. Storch \& Wigglesworth's (2010) findings suggest that affections influence uptake and retention of CF. And the processes of encoding, retrieval and recollection are influenced by emotion (Buchanan, 2007).

To understand and memorize the knowledge that learners have acquired is far from enough if it does not become internalized in the process of learning. A large amount of input must be followed by an equal or more amount of time and effort in output, i.e., keeping practicing will help to make the knowledge intensified. If learners are actively engaged with the deep structure of the material, they are more likely to recall and use these new skills in novel contexts (Cook \& Klipfel, 2015).

The study of the impact of multimodal annotations upon uptake and retention has found that multimodal annotations benefit vocabulary uptake and retention in the realm of computer assisted language learning (CALL) (Akbulut, 2007; Mohsen \& Balakumar, 2011). Paivio's (1991) Dual Coding Theory (DCT) is applied in a research, which reveals that the visual clarification of vocabulary enhances the processing quality and thus is conducive to new words memory. However, Boers et al. (2017) argue that the provision of multimodal annotations is only one of the ways for more attention and retention in memory.

Memorizing vocabulary or grammar is the first step for learners to learn L2 well. AI technology is used to help learners to remember what they learn. Models have been made to simulate human long-term memorization based on the early tenet that memories deteriorate with the passage of time but can be consolidated by repetition spaced in time (Ebbinghaus, 2013). Pavlik \& Anderson (2005) have shown the increased benefit of spacing with increased practice and longer retention intervals in their experiment on the effects of practice and spacing on retention of Japanese-English vocabulary paired associates. Riedesel et al. (2017) use the ACTR model of memorization to simulate learner responses.

\section{$2.3 \mathrm{WCF}$ and $A I$}

CF provided by teachers in L2 learning is simulated by AI CF. Graduated CF is provided in an intelligent computer-assisted language learning (ICALL) environment (Ai, 2017), and the result reveals that the graduated approach to CF contributes to learner self-identification and self-correction in spite that tutor CF is a necessary remedy when the ICALL system occasionally fails to do its part.

Kaplan et al. (1998) utilize AI technology in GRE writing scoring, i.e., in checking sentence construction, analyzing consecutive sentences, and determining the correct grammar. They find that the automatical grammar-checking program is ideal but hard to practice. The correct percentage of many grammar-checking programs amounts for only $35 \%$ to $40 \%$, one program even amounts to $60 \%$ of the errors. Though grammar-checking programs have a high rate of error-detecting inaccuracy, they are useful in aiding writers to spot the potential problems.

Park (2019) compares an AI-based English grammar checker with human raters in WCF, and he finds the grammar checker provides the same, different or wrong feedback compared to the human raters. It suggests that the program is helpful in most cases, but sometimes it is indeed beyond its reach to detect the prevalent grammatical errors or give the correct feedback. Nevertheless, this does not mean that AI-based computer programs in EFL classroom is not possible.

AI is also used in translation in L2 writing. Chon et al. (2021) find that machine translation (MT) in L2 writing is helpful in narrowing the gap of writing ability between the skilled and less skilled learners, facilitating the use of lower frequency words and syntactically more complex sentences and reducing the quantity of grammatical errors. Of course, some mistranslations and poor word choices are unavoidable in MT-translated compositions. To sum up, although AI has some limitations in language learning, it still plays an important role in L2 writing.

Quite different from the previous research on learner cognitive psychology or on AI technology application in L2 teaching and learning, this study integrates L2 learner cognitive psychology with AI technology. Cognitive psychological factors-perceptions, noticing, uptake, initiative, retention and emotion are considered in the process of pigai $\mathrm{CF}$ where natural language processing technology is used together with deep learning and cloud computing technologies (see Fig.1). These factors are assumed to be interrelated and influence one another, which will have an ultimate impact on L2 writing (see Fig. 2). This paper poses the following questions:

1) Do learners usually have the expected cognitive psychology of pigai $\mathrm{CF}$ ?

2) How do learners perceive pigai $\mathrm{CF}$ ? 
3) Can learners notice, understand and memorize pigai $\mathrm{CF}$ ?

4) Are factors of L2 learner cognitive psychology related to one another?

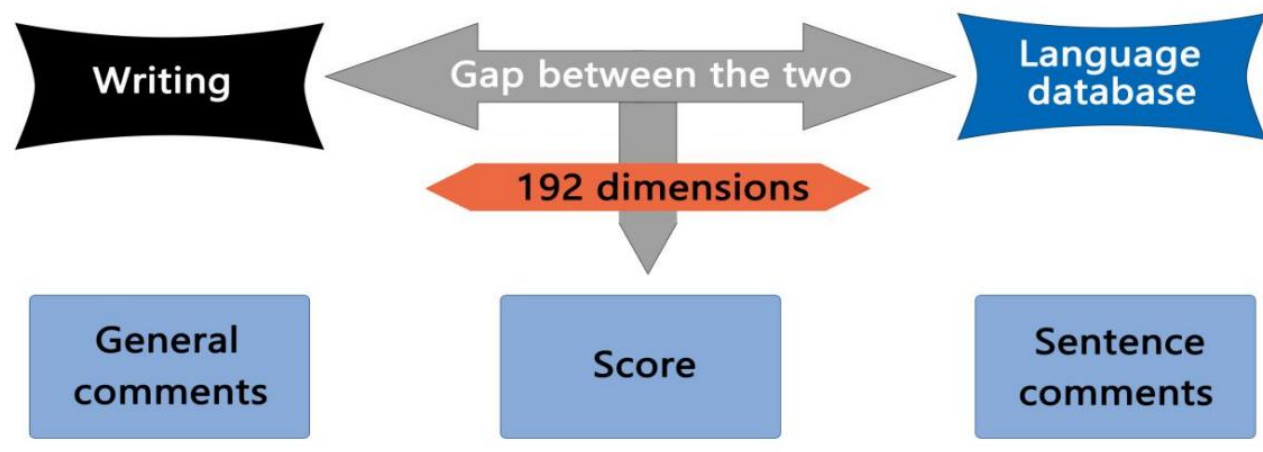

Figure 1. Pigai Grading Principle (Note 1)

Two hypotheses were formulated in order to answer the above questions.

H1: Learners usually have the expected experience in perception, noticing, uptake, initiative, retention and emotion about pigai $\mathrm{CF}$.

H2: Learner perception, noticing, uptake, initiative, retention and emotion of pigai CF are positively related.

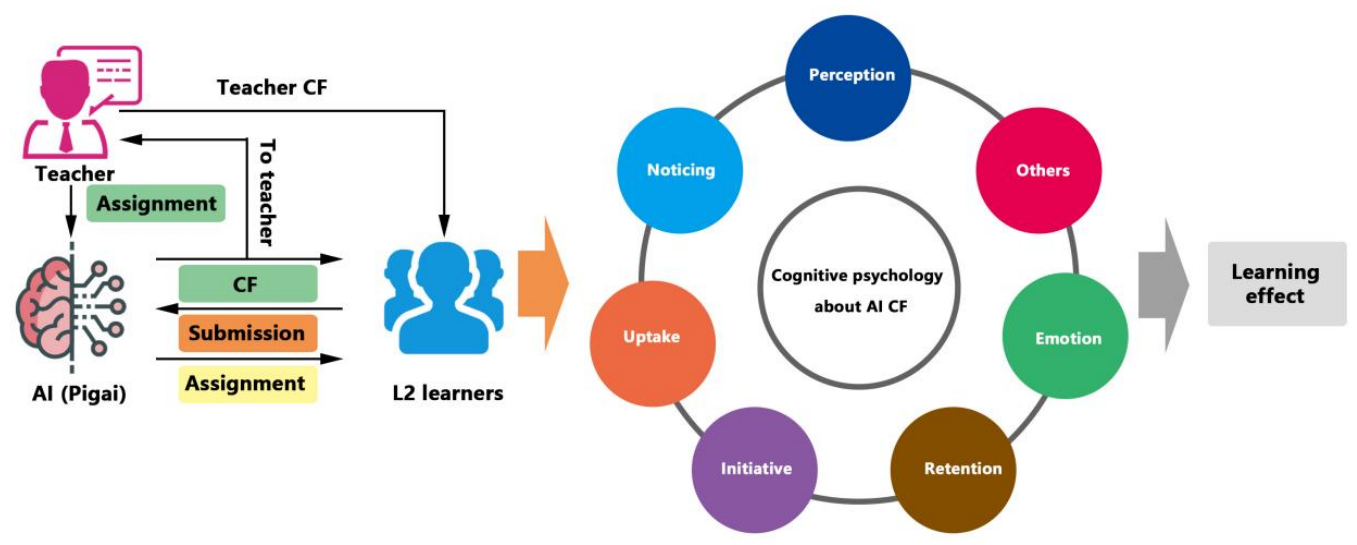

Figure 2. L2 Learner Cognitive Psychology Process about Pigai CF

\section{Method}

The research was made by conducting a questionnaire survey on learner cognitive psychology of pigai WCF. To guarantee the quality of the questionnaire survey, a pilot study was carried out to identify the potential problems and deficiencies in the research design.

\subsection{Pilot Study}

In the pilot study, there were 22 items concerning learner perception, noticing, uptake, initiative, retention and emotion. Through a small sample study of 56 students in AUFE, it was found the Cronbach acoefficient is 0.83 , but $\mathrm{KMO}$ value is below 0.6 , suggesting the reliability of the questionnaire survey is high, but the validity is low. Then the researchers deleted two items whose KMO values were too low, and supplemented four items $(3,5,15$, 21) so as to make the survey more valid and inclusive. Additionally, the researchers revised some of the other items whose KMO values were comparatively low. For example, the original item 2 "Pigai provides $\mathrm{CF}$ and recommends sentence patterns and expressions" was modified into "Pigai provides CF and recommends sentence patterns and expressions, which is of great help to my English writing."

\subsection{Participants, Stimuli and Apparatus}

The formal questionnaire survey was finally conducted in June, 2021 with the participation of 1952 undergraduates (1189 females, 763 males) in AUFE with a college level of proficiency in English, 754 freshmen, 782 sophomores, 406 juniors and 10 seniors. 
In this questionnaire survey (see Appendix), each of the 24 items was followed by five options using a 5-point Likert scale to test learner cognitive psychology about AI WCF. $1=$ This is never true of me. $2=$ This is occasionally true of me. $3=$ This is sometimes true of me. 4=This is usually true of me. $5=$ This is always true of me. There were 13 positive statements and 11 negative statements in the 24 items to obviate the acquiescence on positive items. Participants were required to select one option from the five options in each item that best suited them. Details of item 1-24 were: 1-10: perceptions of pigai, encompassing how learners experience and understand functions (advantages and disadvantages) of pigai; 11-13: noticing and uptake; 14-15: learning initiative; 16-17: memory; 18-24: emotion, including self-esteem, self-confidence, preference of AI or human CF.

The questionnaire survey was distributed, collected and calculated by Wen Juan Xing, an online questionnaire survey platform in China. SPSS software was utilized to analyze the statistical data. In one-sample t-test, the number 4 was taken as the reference value to test whether there was difference between the mean value of each variable and the reference value 4 . Number 4 was chosen as the reference value for it was assumed to be the most appropriate frequency compared with the two extremes 1(never) and 5(always), the low frequency of 2 (occasionally) and middle frequency of 3(sometimes). It was hypothesized that learners usually had the expected experience in perception, noticing, uptake, initiative, retention and emotion of pigai CF. Meanwhile, correlations were separately calculated between perception and all the other factors; between emotion and all the other factors; between noticing and uptake; between initiative and factors of noticing, uptake and retention; between factors of noticing, uptake, initiative and retention.

\section{Results and Discussion}

Tests of reliability and validity showed that this questionnaire survey turned out to be reliable and valid for its Cronbach $\alpha$ coefficient was 0.928 and KMO value was 0.941 .

\subsection{One Sample T-Test}

The questionnaire survey was conducted in class under the supervision of teachers with 1954 returns, but 1952 valid. In one sample t-test, the number 4 was taken as the reference value, and the negative statements of items 3 , $5,8,9,10,13,15,16,17,18,19$ were specially disposed by the system. Then the researchers obtained the following results (see Table 1).

Table 1. One Sample T-Test

\begin{tabular}{llllll}
\hline Item No & Mean & Mean difference & Std. Deviation & $\mathrm{p}$ & Cohen's d \\
\hline 1 & 3.207 & -0.793 & 1.113 & $0.000^{* *}$ & 0.712 \\
2 & 3.13 & -0.87 & 1.076 & $0.000^{* *}$ & 0.808 \\
3 & 2.517 & -1.483 & 1.059 & $0.000^{* *}$ & 1.4 \\
4 & 3.171 & -0.829 & 1.05 & $0.000^{* *}$ & 0.79 \\
5 & 3.199 & -0.801 & 1.048 & $0.000^{* *}$ & 0.764 \\
6 & 3.232 & -0.768 & 1.067 & $0.000^{* *}$ & 0.72 \\
7 & 3.291 & -0.709 & 1.154 & $0.000^{* *}$ & 0.614 \\
8 & 2.706 & -1.294 & 1.097 & $0.000^{* *}$ & 1.179 \\
9 & 3.074 & -0.926 & 1.039 & $0.000^{* *}$ & 0.891 \\
10 & 2.954 & -1.046 & 1.086 & $0.000^{* *}$ & 0.963 \\
11 & 3.231 & -0.769 & 1.03 & $0.000^{* *}$ & 0.747 \\
12 & 3.184 & -0.816 & 1.017 & $0.000^{* *}$ & 0.802 \\
13 & 2.916 & -1.084 & 1.035 & $0.000^{* *}$ & 1.047 \\
14 & 3.053 & -0.947 & 0.975 & $0.000^{* *}$ & 0.971 \\
15 & 3.097 & -0.903 & 1.042 & $0.000^{* *}$ & 0.867 \\
16 & 3.031 & -0.969 & 1.056 & $0.000^{* *}$ & 0.917 \\
17 & 3.537 & -0.463 & 1.018 & $0.000^{* *}$ & 0.455 \\
18 & 2.904 & -1.096 & 1.096 & $0.000^{* *}$ & 1 \\
19 & 2.857 & -1.143 & 1.079 & $0.000^{* *}$ & 1.059 \\
20 & 3.076 & -0.924 & 1.062 & $0.000^{* *}$ & 0.87 \\
21 & 2.967 & -1.033 & 1.032 & $0.000^{* *}$ & 1.001 \\
22 & 3.12 & -0.88 & 1.037 & $0.000^{* *}$ & 0.848 \\
23 & 3.065 & -0.935 & 0.988 & $0.000^{* *}$ & 0.947 \\
24 & 3.131 & -0.869 & 1.042 & $0.000^{* *}$ & 0.834 \\
\hline$* * \mathrm{p}<0.01 ;$ & $\mathrm{d}=0.20, \mathrm{a}$ small effect; d & $0.50, \mathrm{a}$ medium effect; $\mathrm{d}=0.80, \mathrm{a}$ large effect
\end{tabular}


As is shown in the table, each $\mathrm{p}$ is less than 0.01 , meaning there is significant difference between the reference value 4 and the mean in each choice. The maximum mean is 3.537 (item 17), and the minimum mean is 2.517 (item 3). Seventeen items whose means are above 3 but below 4 are respectively 1, 2, 4, 5, 6, 7, 9, 11, 12, 14, 15, 16, 17, 20, 22, 23 and 24. Those which are above 2 but below 3 are items 3, 8, 10, 13, 18, 19 and 21.

Cohen's d (effect size) is used to further test the difference between the mean and the reference value 4 . It finds that Cohen's d ranges from 0.455 (small effect, item 17) to 1.4 (large effect, item 3). As for perception, effects vary from items 1, 4, 5, 6 and 7 medium to 2, 38,9 and 10 large. As to noticing and uptake, effects are different too with item 11 medium, 12 and 13 large. For initiative, both items 14 and 15 are large. Regarding retention, items 16 and 17 are large and small respectively. For emotion, all the items are large.

Therefore, both $\mathrm{p}$ values and Cohen's $d$ indicate that there exists significant difference between the mean and the reference value 4, i.e., averagely learners only occasionally or sometimes have the same experience of cognitive psychology of AI WCF as is presented in the survey. These results violate $\mathrm{H}_{1}$ that learners usually have the expected experience of perception, noticing, uptake, retention, and emotion of pigai WCF. Then the researchers decided to have interviews with the respondents.

\subsection{Interviews}

To find out the reasons why all the means were below 4, random interviews with 15 respondents were conducted about the same 24 items in the questionnaire survey in July, 2021. The interviews focused on the choices never, occasionally and sometimes for positive statements but always, usually and sometimes for negative statements because these choices in each item (except item 17) added up to over $50 \%$ as was reflected in the report (Note 2) of the questionnaire survey, which would have a direct impact on the outcome of the survey. The results of the interviews are summarized as follows:

Perception: Pigai is not efficient all the time. It is lack of emotion and interaction, unable to distinguish the indiscernible errors. Of course, it is true that pigai provides a lot of synonym discrimination and recommends many sentences patterns, but many are very similar and simple, which are time-wasting and may not be suitable for the context of the current writing. Since all the synonym discriminations are interpreted in Chinese, learners will have to spend some time looking them up in an all English dictionary to find out the authentic usage. Some learners admit pigai's advantage of submitting the essay time and again to get a high score, but the score will be raised at most five points if learners only correct the mistakes without changing the basic structure of the essay. Sometimes even if learners do correct the mistake as was suggested, yet often an annotation will show that it is still wrong. After scrutinizing pigai, researchers find that an incorrect sentence is usually singled out for grammar or spelling or semantic or other mistakes, and a warning is provided by using metalingual $\mathrm{CF}$, and sometimes this warning is vague, which is hard for some learners, esp., those with low level of language proficiency to find out or understand. The following is an example from pigai.

Original sentence: So, the globalization's common definition is the procedure of integrating the movement of goods, capital and jobs in the global scope...

Annotation: article warning in Chinese — an unnecessary article, please check the (see the following snapshot).

\begin{tabular}{|c|}
\hline 学习提示(17) \\
\hline 推荐表达(13) \\
\hline 冠词警示(4) \\
\hline 拓展辩析(2) \\
\hline 句子警示(2) \\
\hline
\end{tabular}

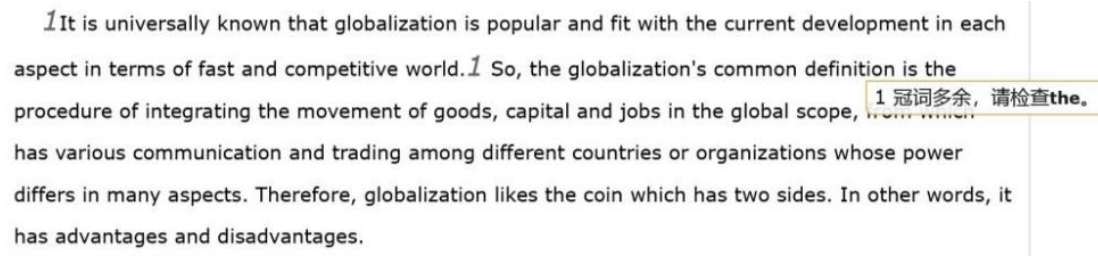

Figure 3. A Snapshot from Pigai

As can be seen, it is not easy for learners, esp., those with low level proficiency to know the meaning of the technical term article, let alone to find out which article is unnecessary since there are four in this sentence.

Noticing \& uptake: Learners can notice and be aware of their mistakes after pigai correction if they spend time and effort reading them carefully. But not all the learners can understand the mistakes at a deep level. The problem with pigai is that it fails to adapt to L2 learners with different levels of English proficiency.

Initiative: Both human $\mathrm{CF}$ and pigai require learners to practise enough times before they can avoid the same mistake next time even if they have paid attention to their mistakes. But for some learners, it is not pigai CF but the score that is what they care about most. Accordingly, initiative influences attention, which in turn, affects outcome. 
Retention: Some learners consider that retention about pigai or human CF is mostly contingent on whether they have pondered over their mistakes. That's to say, retention is linked with initiatives. But comparatively speaking, teacher $\mathrm{CF}$ are more elaborate, concise, interactive, and impressive. It outweighs pigai in memorizing for its unique forms of sight, sound, and even touch.

Emotion: Some learners don't mind whether their self-esteem or self-confidence is dampened because they think learners should not worry about losing face to learn L2 well. Others with low level of English proficiency but high self-esteem hold that both teacher and pigai CF can sometimes hurt their self-esteem or self-confidence, for although they thought they had corrected the mistakes as were suggested, esp., the stupid mistakes time and again, it often turned out they were still notified that they failed to give the correct expression, which rendered them frustrated and depressed. Some find great changes have taken place for pigai, and they say that nowadays pigai is able to detect whether the essay keeps to the point or not. They admit that emotional communication is important but not necessary in error correction. However, some learners perceive human CF is better than AI CF in that the former can provide targeted extended knowledge beside the specific $\mathrm{CF}$, which distinguishes fundamentally from the blind or untargeted one in the latter. What's more important is that human error correction tells learners how to write, including what the learner intends to express, how to organize an essay, how to develop a topic sentence or a paragraph and how to knit the paragraphs well, etc., which are very critical for L2 writing.

Research on L2 learning finds that learner performance will not be enhanced by feedback unless learners have an opportunity to benefit from feedback (Jennings \& Jacoby, 2003; Kantner \& Lindsay, 2010). Results of the interviews with 15 respondents suggest that pigai is beneficial to L2 writing, but there is still much room for it to improve to be deeply integrated with human WCF.

\subsection{Correlation of Factors in Cognitive Psychology}

Then the researchers explored correlations 1) between perception and all the other factors of cognitive psychology; 2) between emotion and all the other factors of cognitive psychology; 3) between noticing and uptake; 4) between initiative and factors of noticing, uptake and retention; 5) between factors of noticing, uptake, initiative and retention.

Firstly, perception was thought to be essential and closely relevant to all the other factors of cognitive psychology. Thus, perception was regarded as variable $\mathrm{X}$, factors of noticing, uptake, initiative, retention and emotion as variable $\mathrm{Y}$, we obtained the following results (see Table 2).

Table 2. Perception vs Noticing, Uptake, Initiative, Retention and Emotion

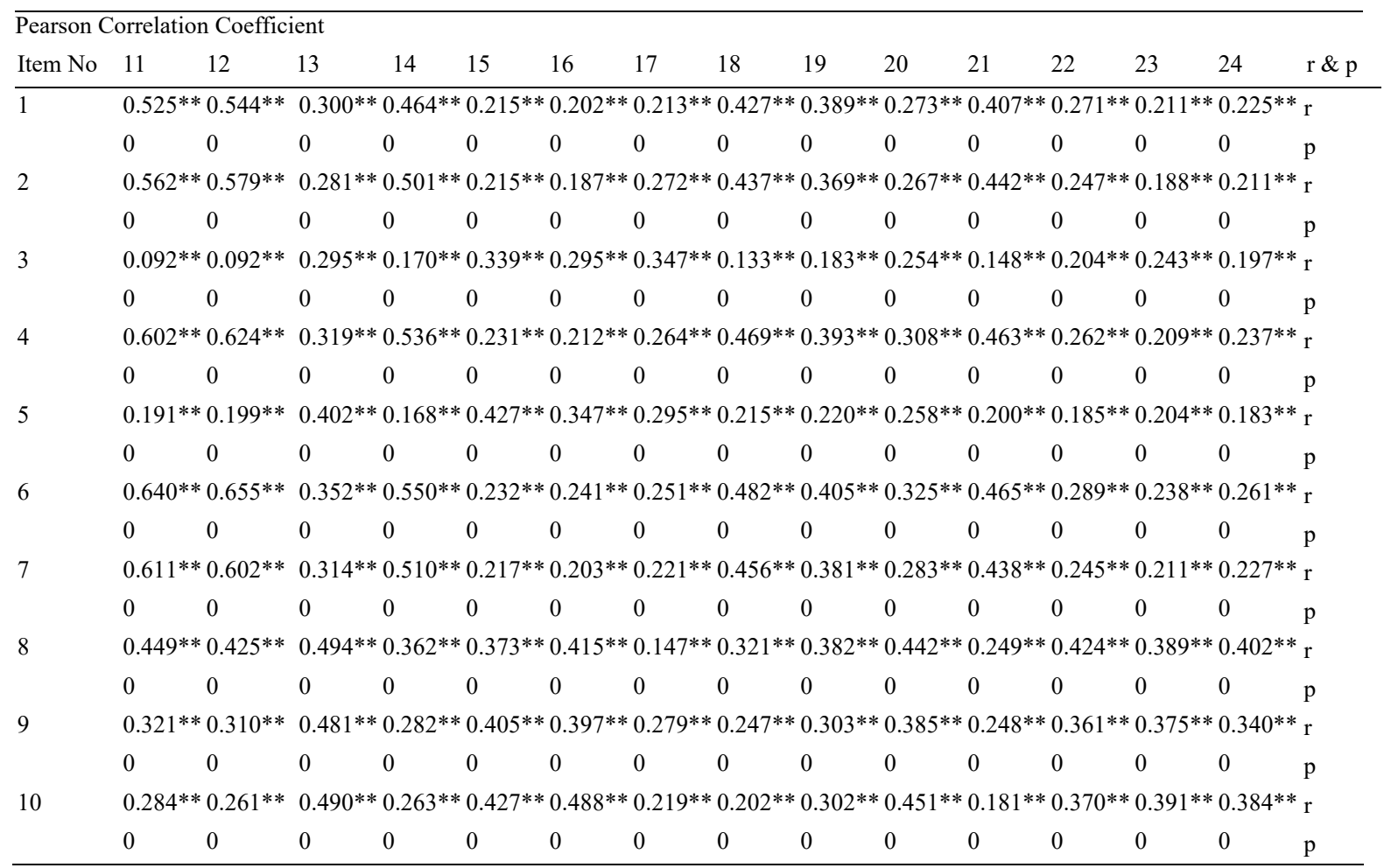

${ }^{*} \mathrm{p}<0.05 ; * * \mathrm{p}<0.01 ; \mathrm{r}>0$, positive; $|\mathrm{r}|>0.95$, significant; $|\mathrm{r}| \geq 0.8$, high; $0.5 \leq|\mathrm{r}| 0.8$, moderate; $0.3 \leq|\mathrm{r}| 0.5$, low; $|\mathrm{r}|$ 0.3 , weak 
As is shown in the table, all the $\mathrm{p}$ values are less than 0.01 , suggesting significant correlations between perception and noticing, uptake, initiative, retention and emotion. And all the $\mathrm{r}$ values are more than 0 , suggesting positive correlations between perception and noticing, uptake, initiative, retention and emotion although the degrees vary from moderate $(6 \mathrm{vs} 12,0.655)$ to low ( 3 vs $18,0.133)$ correlations. These results accept $\mathrm{H}_{2}$.

Secondly, emotion was assumed to be vital to perception, noticing, uptake, initiative and retention. Therefore, emotion was considered as variable $\mathrm{X}$, factors of perception, noticing, uptake, initiative and retention were variable $\mathrm{Y}$, we obtained the following results (see Table 3 ).

Table 3. Emotion vs Perception, Noticing, Uptake, Initiative and Retention

\begin{tabular}{|c|c|c|c|c|c|c|c|c|c|c|c|c|c|c|c|c|c|c|}
\hline \multicolumn{19}{|c|}{ Pearson Correlation Coefficient } \\
\hline Item No 1 & & 2 & 3 & 4 & 5 & 6 & 7 & 8 & 9 & 10 & 11 & 12 & 13 & 14 & 15 & 16 & 17 & $r \& p$ \\
\hline \multirow{2}{*}{18} & $0.427 * *$ & $0.437^{* *}$ & $0.133^{* *}$ & $0.469 * *$ & $0.215^{* *}$ & $0.482 * *$ & $0.456^{* *}$ & $0.321^{* *}$ & $0.247 * *$ & $0.202 * *$ & $0.485^{* *}$ & $0.510 * *$ & $0.322 * *$ & $0.506^{* *}$ & $0.286^{* *}$ & $0.294 * *$ & $0.368 * *$ & $r$ \\
\hline & 0 & 0 & 0 & 0 & 0 & 0 & 0 & 0 & 0 & 0 & 0 & 0 & 0 & 0 & 0 & 0 & 0 & $\mathrm{p}$ \\
\hline \multirow{2}{*}{19} & $0.389 * *$ & $0.369 * *$ & $0.183^{* *}$ & $0.393 * *$ & $0.220 * *$ & $0.405^{* *}$ & $0.381 * *$ & $0.382 * *$ & $0.303 * *$ & $0.302 * *$ & $0.429 * *$ & $0.436 * *$ & $0.343 * *$ & $0.438 * *$ & $0.291 * *$ & $0.347 * *$ & $0.248^{* *}$ & $r$ \\
\hline & 0 & 0 & 0 & 20 & 0 & 0 & 0 & 0 & 0 & 0 & 0 & 0 & 0 & 0 & 0 & 0 & 0 & $\mathrm{p}$ \\
\hline \multirow[t]{2}{*}{20} & $0.273^{* *}$ & $0.267^{* *}$ & $0.254^{* *}$ & $0.308^{* *}$ & $0.258^{* *}$ & $0.325^{* *}$ & $0.283^{* *}$ & $0.442 * *$ & $0.385 * *$ & $0.451^{* *}$ & $0.343^{* *}$ & $0.341 * *$ & $0.406^{* *}$ & $0.352 * *$ & $0.385^{* *}$ & $0.539^{* *}$ & $0.191 * *$ & $r$ \\
\hline & 0 & 0 & 0 & 0 & 0 & 0 & 0 & 0 & 0 & 0 & 0 & 0 & 0 & 0 & 0 & 0 & 0 & $\mathrm{p}$ \\
\hline \multirow{2}{*}{21} & $0.407 * *$ & $0.442 * *$ & $0.148 * *$ & $0.463^{* *}$ & $0.200 * *$ & $0.465^{* *}$ & $0.438^{* *}$ & $0.249 * *$ & $0.248^{* *}$ & $0.181^{* *}$ & $0.439 * *$ & $0.475^{* *}$ & $0.286^{* *}$ & $0.459 * *$ & $0.289 * *$ & $0.205^{* *}$ & $0.436^{* *}$ & $r$ \\
\hline & 0 & 0 & 0 & 0 & 0 & 0 & 0 & 0 & 0 & 0 & 0 & 0 & 0 & 0 & 0 & 0 & 0 & $\mathrm{p}$ \\
\hline \multirow{2}{*}{22} & $0.271 * *$ & $0.247^{* *}$ & $0.204 * *$ & $0.262 * *$ & $0.185^{* *}$ & $0.289 * *$ & $0.245 * *$ & $0.424 * *$ & $0.361 * *$ & $0.370^{* *}$ & $0.312 * *$ & $0.291 * *$ & $0.375^{* *}$ & $0.296 * *$ & $0.291 * *$ & $0.437 * *$ & $0.147^{* *}$ & $r$ \\
\hline & 0 & 0 & 0 & 0 & 0 & 0 & 0 & 0 & 0 & 0 & 0 & 0 & 0 & 0 & 0 & 0 & 0 & $\mathrm{p}$ \\
\hline \multirow{2}{*}{23} & $0.211 * *$ & $0.188^{* *}$ & $0.243 * *$ & $0.209 * *$ & $0.204 * *$ & $0.238^{* *}$ & $0.211 * *$ & $0.389 * *$ & $0.375 * *$ & $0.391 * *$ & $0.257^{* *}$ & $0.244 * *$ & $0.377^{* *}$ & $0.256^{* *}$ & $0.296^{* *}$ & $0.437 * *$ & $0.129 * *$ & $r$ \\
\hline & 0 & 0 & 0 & 0 & 0 & 0 & 0 & 0 & 0 & 0 & 0 & 0 & 0 & 0 & 0 & 0 & 0 & $\mathrm{p}$ \\
\hline \multirow{2}{*}{24} & $0.225^{* *}$ & $0.211^{* *}$ & $0.197 * *$ & $0.237 * *$ & $0.183^{* *}$ & $0.261^{* *}$ & $0.227 * *$ & $0.402 * *$ & $0.340 * *$ & $0.384 * *$ & $0.279 * *$ & $0.245^{* *}$ & $0.362^{* *}$ & $0.282 * *$ & $0.296^{* *}$ & $0.449 * *$ & $0.121 * *$ & $r$ \\
\hline & 0 & 0 & 0 & 0 & 0 & 0 & 0 & 0 & 0 & 0 & 0 & 0 & 0 & 0 & 0 & 0 & 0 & $\mathrm{p}$ \\
\hline
\end{tabular}

As is shown in the table, all the $\mathrm{p}$ values are less than 0.01, suggesting significant correlations between emotion and perception, noticing, uptake, initiative and retention. And all the $\mathrm{r}$ values are more than 0 , suggesting positive correlations between emotion and perception, noticing, uptake, initiative and retention although the degrees vary from moderate ( 20 vs $16,0.539)$ to low $(24$ vs $17,0.121)$ correlations. The results accept $\mathrm{H}_{2}$.

Thirdly, noticing was thought to be closely related to uptake. Accordingly, noticing was taken as variable X, uptake as variable $\mathrm{Y}$, and we got the following results (see Table 4).

Table 4. Noticing vs Uptake

\begin{tabular}{llll}
\hline \multicolumn{3}{l}{ Pearson Correlation Coefficient } \\
Item No & 12 & 13 & $\mathrm{r} \& \mathrm{p}$ \\
\hline 11 & $0.778^{* *}$ & $0.374^{* *}$ & $\mathrm{r}$ \\
& 0 & 0 & $\mathrm{p}$ \\
\hline
\end{tabular}

As is indicated in the table, two $\mathrm{p}$ values are less than 0.01, suggesting significant correlations between noticing and uptake. And two $r$ values were more than 0 , suggesting positive correlations between noticing and uptake. There is a moderate (0.778) correlation between items 11 and 12, but a low (0.374) one between 11 and 13 . These results accept $\mathrm{H}_{2}$.

Fourthly, initiative was supposed to play an important part in noticing, uptake and retention. So initiative was taken as variable $\mathrm{X}$, factors of noticing, uptake and retention were variable $\mathrm{Y}$, the results are as follows (see Table 5):

Table 5. Initiative vs Noticing, Uptake and Retention

\begin{tabular}{lllllll}
\multicolumn{2}{l}{ Pearson Correlation Coefficient } \\
Item No & 11 & 12 & 13 & 16 & 17 & $\mathrm{r} \& \mathrm{p}$ \\
\hline \multirow{2}{*}{14} & $0.600^{* *}$ & $0.680^{* *}$ & $0.314^{* *}$ & $0.287^{* *}$ & $0.356^{* *}$ & $\mathrm{r}$ \\
& 0 & 0 & 0 & 0 & 0 & $\mathrm{p}$ \\
15 & $0.264^{* *}$ & $0.235^{* *}$ & $0.537^{* *}$ & $0.518^{* *}$ & $0.386^{* *}$ & $\mathrm{r}$ \\
& 0 & 0 & 0 & 0 & 0 & $\mathrm{p}$ \\
\hline
\end{tabular}

It is found in the table that all the $\mathrm{p}$ values are less than 0.01 , suggesting significant correlations between initiative and noticing, uptake and retention. All the $\mathrm{r}$ values are more than 0 , suggesting positive correlations 
between initiative and noticing, uptake and retention though the degrees of correlation vary from moderate (14 vs $12,0.680)$ to low $(15$ vs $12,0.235)$ correlation. These results accept $\mathrm{H}_{2}$.

Finally, it was hypothesized that if learners noticed pigai CF, understood it, and learned actively, they would memorize it. Thus factors of noticing, uptake, initiative were taken as variable $\mathrm{X}$, and retention as variable $\mathrm{Y}$, we got the following results (see Table 6).

Table 6. Noticing, Uptake, Initiative vs Retention

\begin{tabular}{llll}
\multicolumn{2}{l}{ Pearson Correlation Coefficient } \\
Item No & 16 & 17 & $\mathrm{r} \& \mathrm{p}$ \\
\hline 11 & $0.241^{* *}$ & $0.255^{* *}$ & $\mathrm{r}$ \\
& 0 & 0 & $\mathrm{p}$ \\
12 & $0.240^{* *}$ & $0.300^{* *}$ & $\mathrm{r}$ \\
& 0 & 0 & $\mathrm{p}$ \\
13 & $0.482^{* *}$ & $0.243^{* *}$ & $\mathrm{r}$ \\
& 0 & 0 & $\mathrm{p}$ \\
14 & $0.287^{* *}$ & $0.356^{* *}$ & $\mathrm{r}$ \\
& 0 & 0 & $\mathrm{p}$ \\
15 & $0.518^{* *}$ & $0.386^{* *}$ & $\mathrm{r}$ \\
& 0 & 0 & $\mathrm{p}$
\end{tabular}

It is revealed in the table that all the $\mathrm{p}$ values are less than 0.01 , suggesting significant correlations between noticing, uptake, initiative and retention. Although the degrees of correlation range from moderate (15 vs 16 , $0.518)$ to low $(12$ vs $16,0.240)$ correlation, all the $\mathrm{r}$ values are more than 0 , suggesting positive correlations between noticing, uptake, initiative and retention. These results accept $\mathrm{H}_{2}$.

The results of positive correlations of perception, noticing, uptake, initiative, retention and emotion in AI WCF conform to the previous findings (Buchanan, 2007; Cook \& Klipfel, 2015; Fenske et al., 2005; Fredricks et al., 2004; Kiss et al., 2007; Langeslag et al., 2008; Liu et al., 2009; Storch \& Wigglesworth, 2010; Zhou et al., 2007) factors of cognitive psychology are bound and interrelated and might influence learning effects, though the effects of cognitive psychology on learning are implicitly embodied in this paper. Positive perceptions or emotions are often associated with positive outcomes. Likewise, learners who manifest more noticing develop more than those who manifest less noticing (Mackey, 2006). Izumi (2002) evidences in an experiment to compare the effects of output and enhanced input on noticing and development that subjects demonstrate more noticing and more learning than do controls, and that noticing is a first step in the learning process. Moreover, uptake and retention in WCF are affected by linguistic and affective factors (Langeslag et al., 2008), and initiatives motivate learners to spare time and take advantage of opportunity to repeat and practice new knowledge (Amrhein \& Nassaji, 2010).

\section{Conclusion}

It is concluded that AI technology is playing an increasingly important role in L2 WCF and will probably replace human WCF in the future. While integration of L2 education and technology is emphasized nowadays, and a lot of achievements have been made in $\mathrm{AI}$ application in L2 teaching and learning, it is still worth noting that there is still some gap between AI technology and L2 learner cognitive psychology of AI WCF. Therefore, in the future it will be more demanding and challenging for AI researchers to perfect AI machines used in L2 WCF. The future research will be more human-oriented, systematic, combining the existing cognitive psychology and teaching theories with the relatively independent technology that has a better understanding of the learning process and cognitive psychology of L2 learners so as to help them learn more efficiently and effectively. The future AI WCF requires that there should be a deep integration of AI technology with human WCF, and that language used in AI WCF should be more concrete, explicit and to the point rather than be metalingual, implicit and redundant so that the learners at different levels of proficiency can really understand the afforded CF and improve their writing skills.

\section{Declarations}

\subsection{Availability of Data and Materials}

The authors agree to sharing their data.

\subsection{Funding}

All sources of funding for the research reported are declared. 


\section{Acknowledgments}

This research is funded by Foreign Language Project Commissioned to Education Department of Anhui Province by Shanghai Foreign Language Education Press (SK2018A1136); by The Key Anhui Humanities and Social Sciences Planned Project Fund (AHSKZ2018D16); by The Key Scientific Research Fund of AUFE (ACKY1805ZDA). Special thanks go to peer reviewers and all the participants and teachers who have contributed to the completion of this paper.

\section{References}

Ai, H. (2017). Providing graduated corrective feedback in an intelligent computer-assisted language learning environment. ReCALL, 29(3), 313-334. https://doi.org/10.1017/S095834401700012X

Akbulut, Y. (2007). Effects of multimedia annotations on incidental vocabulary learning and reading comprehension of advanced learners of English as a foreign language. Instructional Science, 35, 499-517. https://doi.org/10.1007/s11251-007-9016-7

Amrhein, H., \& Nassaji, H. (2010). Written corrective feedback: What do students and teachers think is right and why? Canadian Journal of Applied Linguistics, 13(2), 95-127. Retrieved from https://journals.lib.unb.ca/index.php/CJAL/article/view/19886

Boers, F. W., Grimshaw, P., Grimshaw, G., \& Siyanova-Chanturia, A. (2017). On the benefits of multimodal annotations for vocabulary uptake from reading. Computer Assisted Language Learning, 30(7), 709-725. https://doi.org/10.1080/09588221.2017.1356335

Buchanan, T. W. (2007). Retrieval of emotional memories. Psychological Bulletin, 133, 761-779. https://doi.org/10.1037/0033-2909.133.5.761

Chon, Y. V., Shin, D., \& Kim, G. E. (2021). Comparing L2 learners' writing against parallel machine Translated texts: Raters' assessment, linguistic complexity and errors. System, 96, 1-12. https://doi.org/10.1016/j.system.2020.102408

Cook, D. B., \& Klipfel, K. M. (2015). How do our students learn? An outline of a cognitive psychological model for information literacy instruction. Reference and User Services Quarterly, 55(1), 34-41. https://doi.org/10.5860/rusq.55n1.34

Cotos, E. (2010). Automated writing evaluation for non-native speaker English academic writing: The case of $I A D E$ and its formative feedback. Graduate Theses and Dissertations. Paper 11630, Iowa State University. Retrieved from https://www.learntechlib.org/p/122265

Cui, Y., \& Wang, S. (2021). Machine learning-based student emotion recognition for business English Class. iJET, 16(12), 94-107. https://doi.org/10.3991/ijet.v16i12.23313

Ebbinghaus, H. (2013). Memory: a contribution to experimental psychology. Annals of Neurosciences, 20(4), 155-156. https://doi.org/10.5214/ans.0972.7531.200408

Fenske, M. J., Raymond, J. E., Kessler, K., Westoby, N., \& Tipper, S. P. (2005). Attentional inhibition Has social-emotional consequences for unfamiliar faces. Psychological Science, 16(10), 753-758. https://doi.org/10.1111/j.1467-9280.2005.01609.x

Fredricks, J., Blumenfeld, P. C., \& Paris, A. (2004). School engagement: Potential of the concept, state of the evidence. Review of Educational Research, 74, 59-109. https://doi.org/10.3102/00346543074001059

Izumi, S. (2002). Output, input enhancement, and the noticing hypothesis: An experimental study on ESL relativization. Studies in Second Language Acquisition, 24, 541-577. https://doi.org/10.1017/S0272263102004023

Jennings, J. M., \& Jacoby, L. L. (2003). Improving memory in older adults: Training recollection. Neuropsychological Rehabilitation, 13, 417-440. https://doi.org/10.1080/09602010244000390

Kantner, J., \& Lindsay, D. S. (2010). Can corrective feedback improve recognition memory? Memory \& Cognition, 38(4), 389-406. https://doi.org/10.3758/MC.38.4.389

Kaplan, R. M., Wolff, S., Burstein, J. C., Lu, C., Rock, D., \& Kaplan, B. (1998). Scoring essays automatically using surface features. ETS Research Report Series, 2, 1-12. https://doi.org/10.1002/j.2333-8504.1998.tb01788.x

Kiss, M., Goolsby, B., Raymond, J. E., Shapiro, K. L., Silvert, L., Nobre, A. C., Fragopanagos, N., Taylor, J. G., \& Eimer, M. (2007). Efficient attentional selection predicts distractor devaluation: ERP evidence for a 
direct link between attention and emotion. Journal of Cognitive Neuroscience, 19(8), 1316-1322. https://doi.org/10.1162/jocn.2007.19.8.1316

Koltovskaia, S. (2020). Student engagement with automated written corrective feedback (AWCF) provided by Grammarly: A multiple case study. Assessing Writing, 44, 1-12. https://doi.org/10.1016/j.asw.2020.100450

Langeslag, S. J. E., Franken, I. H. A., \& van Strien, J. W. (2008). Dissociating love-related attention from task-related attention: An event-related potential oddball study. Neuroscience Letters, 431(3), 236-240. https://doi.org/10.1016/j.neulet.2007.11.044

Liu, Y., Fu, Q. F., \& Fu, X. L. (2009). The interaction between cognition and emotion. Chinese Science Bulletin, 54, 4102-4116. https://doi.org/10.1007/s11434-009-0632-2

Mackey, A. (2006). Feedback, noticing and instructed second language learning. Applied Linguistics, 27, 405-530. https://doi.org/10.1093/applin/ami051

Mohsen, M. A., \& Balakumar, M. (2011). A review of multimedia glosses and their effects on L2 vocabulary acquisition in CALL literature. ReCALL, 23, 135-159. https://doi.org/10.1017S095/834401100005X

Niedenthal, P. M. (2007). Embodying emotion. Science, 316(5827), 1002-1005. https://doi.org/10.1126/science.1136930

Paivio, A. (1991). Dual coding theory: Retrospect and current status. Canadian Journal of Psychology, 45, 255-287. https://doi.org/10.1037/h0084295

Park, J. (2019). An AI-based English grammar checker vs. human raters in evaluating EFL learners' writing. Multimedia-Assisted Language Learning, 22(1), 112-131.

Pavlik, P. I., \& Anderson, J. R. (2005). Practice and forgetting effects on vocabulary memory: An activation-based model of the spacing Effect. Cognitive Science, 29(4), 559-586. https://doi.org/10.1207/s15516709 $\operatorname{cog} 0000 \_14$

Pessoa, L. (2008). On the relationship between emotion and cognition. Nature Reviews Neuroscience, 9, 148-158. https://doi.org/10.1038/nrn2317

Riedesel, M. A., Zimmerman, N., Baker, R., Titchener, T., \& Cooper, J. (2017). Using a model for learning and memory to simulate learner response in spaced practice. In E. André, R. Baker, X. Hu, M. Rodrigo \& B. du Boulay (Eds.), Artificial Intelligence in Education. AIED 2017. Lecture Notes in Computer Science (pp. 644-649). Cham: Springer. https://doi.org/10.1007/978-3-319-61425-0_81

Schmidt, R. (1990). The role of consciousness in second language learning. Applied Linguistics, 11, 129-158. https://doi.org/10.1093/applin/11.2.129

Schmidt, R. (2012). Attention, awareness, and individual differences in language learning. In W. M. Chan, K. N. Chin, S. K. Bhatt \& I. Walker (Eds.), Perspectives on Individual characteristics and Foreign Language Education (pp. 27-50). Berlin, Boston: De Gruyter Mouton. https://doi.org/10.1515/9781614510932.27

Storch, N., \& Wigglesworth, G. (2010). Learners' processing, uptake, and retention of corrective feedback on writing: Case Studies. Studies in Second Language Acquisition, 32(2), 303-334. https://doi.org/10.1017/S0272263109990532

Tomlin, R. S., \& Villa, V. (1994). Attention in cognitive science and second language acquisition. Studies In Second Language Acquisition, 16(2), 183-203. https://doi.org/10.1017/S0272263100012870

Zhang, Y. (2019). AI technology applied in evaluating English writings. Artificial Intelligent View, 3, 86-94.

Zhang, Z., \& Hyland, K. (2018). Student engagement with teacher and automated feedback on L2 writing. Assessing Writing, 36, 90-102. https://doi.org/10.1016/j.asw.2018.02.004

Zhou, H., Wan, L., \& Fu, X. (2007). Generalized "Stigma": Evidence for devaluation-by-inhibition hypothesis from implicit learning. The Proceedings of 2nd International Conference on Affective Computing and Intelligent Interaction (ACII2007). Berlin Heidelberg: Springer-Verlag, 690-697. https://doi.org/10.1007/978-3-540-74889-2_60

\section{Notes}

Note 1. Pigai (www,pigai.org) is an influential online system for correcting English essays automatically by computer, which has customers in many universities in China. It has cumulatively corrected nearly four hundred million essays up to January, 2018 according to its report. It has been applied in our university by almost half of 
our English teachers who are adaptive to AI technology in learner essay correction. But it is not practiced by those who believe more in human brain. The respondents in this questionnaire survey are familiar with this system for it has been used by their teachers.

Its grading principles are to compare and analyze the learner corpus with the standard one, measure the gap between them and transform the gap mapping to the concrete score, general comments, sentence comments and other feedback that can be understood by the learner (Zhang, 2019).

Note 2 . The report of the questionnaire survey is available if necessary. 


\section{Appendix}

\section{A Questionnaire Survey on L2 Learner Cognitive Psychological Factors About Pigai WCF}

Dear students, the following is an anonymous questionnaire survey on L2 learner cognitive psychological factors about pigai writing corrective feedback (WCF). There are no right or wrong answers. Please choose carefully one of the choices in each item that fits you. $1=$ This is never true of me. $2=$ This is occasionally true of me. $3=$ This is sometimes true of me. 4=This is usually true of me. 5=This is always true of me. The data collected will be used in our scientific research, and your options will be appreciated and are of vital importance to our research. Thank you for your time!

\section{Perception}

1. Pigai is efficient for its automatic and immediate rating so that learners can see CF and evaluation immediately.
A. 1
B. 2
C. 3
D. 4
E. 5

2. Pigai provides $\mathrm{CF}$ and recommends sentence patterns and expressions, which is of great help to my English writing.
A. 1
B. 2
C. 3
D. 4
E. 5

3. Sentence patterns and expressions recommended by pigai are so simple that they are not helpful to improving my English writing.
A. 1
B. 2
C. 3
D. 4
E. 5

4. Apart from giving CF, pigai provides extended discrimination, such as synonym discrimination, which is of great help to my English writing.
A. 1
B. 2
C. 3
D. 4
E. 5

5. There are so plenty of expanded knowledge and analysis provided by pigai that I can not afford time to read them carefully.
A. 1
B. 2
C. 3
D. 4
E. 5

6. Pigai can detect mistakes in grammar, collocation, part of speech, spelling, capitalization, punctuation and so on, which is of great help to my English writing.
A. 1
B. 2
C. 3
D. 4
E. 5

7. I am very pleased with pigai for where I can revise and submit my writing repeatedly until my score is satisfactory.
A. 1
B. 2
C. 3
D. 4
E. 5

8. The error correction of pigai is not accurate enough. For example, "It seems that..." is often used to comment a sentence or an expression. It would be much better if teacher comments could be furnished.
A. 1
B. 2
C. 3
D. 4
E. 5

9. Pigai can not identify the indiscernible errors. For instance, it can not spot "What" is missing in the sentence "(What) I want to say is...."
A. 1
B. 2
C. 3
D. 4
E. 5

10. Pigai is very mechanical, and there is almost no emotional communication or interaction between pigai and learners.
A. 1
B. 2
C. 3
D. 4
E. 5

Noticing \& uptake

11. I can notice and be aware of my mistakes after pigai correction.
A. 1
B. 2
C. 3
D. 4
E. 5

12. I can notice and be aware of my mistakes, and understand the mistakes after pigai correction.
A. 1
B. 2
C. 3
D. 4
E. 5

13. I can't really understand my mistakes at a deep level owing to lacking interaction with pigai even if I can notice and be aware of them after correction.
A. 1
B. 2
C. 3
D. 4
E. 5 


\section{Initiative}

14. I will carefully examine my mistakes after pigai correction, and will avoid making the same mistake again.
A. 1
B. 2
C. 3
D. 4
E. 5

15. I will not carefully examine my mistakes after pigai correction. As a result, I will make the same mistake again.
A. 1
B. 2
C. 3
D. 4
E. 5

Retention

16. I can't memorize pigai $\mathrm{CF}$, but can remember human $\mathrm{CF}$ like teacher or peer $\mathrm{CF}$.
A. 1
B. 2
C. 3
D. 4
E. 5

17. I can't remember human $\mathrm{CF}$, but can remember pigai $\mathrm{CF}$.
A. 1
B. 2
C. 3
D. 4
E. 5

\section{Emotion}

18. Compared with human CF, pigai will not hurt my self-esteem, self-confidence or dampen my enthusiasm for learning.
A. 1
B. 2
C. 3
D. 4
E. 5

19. Human CF will not hurt my self-esteem, self-confidence or dampen my enthusiasm for learning.
A. 1
B. 2
C. 3
D. 4
E. 5

20. Compared with pigai, I prefer human $\mathrm{CF}$ because human correction has emotional communication.
A. 1
B. 2
C. 3
D. 4
E. 5

21. Compared with human CF, I prefer pigai because it provides expansion besides error correction.
A. 1
B. 2
C. 3
D. 4
E. 5

22. Compared with pigai, I prefer human $\mathrm{CF}$ because human correction can find the errors in structure and organization.
A. 1
B. 2
C. 3
D. 4
E. 5

23. I prefer human $\mathrm{CF}$ because human correction can find logical and cohesive errors.
A. 1
B. 2
C. 3
D. 4
E. 5

24. I prefer human CF because human correction can find whether the content of the essay consists with the topic.
A. 1
B. 2
C. 3
D. 4
E. 5

\section{Copyrights}

Copyright for this article is retained by the author(s), with first publication rights granted to the journal.

This is an open-access article distributed under the terms and conditions of the Creative Commons Attribution license (http://creativecommons.org/licenses/by/4.0/). 